FORSKNING

\title{
Manglande registrering av fall i sjukeheim
}

\author{
Sissel Hjelle Øygard \\ Høgskulelektor \\ Avdeling for helsefag, Høgskulen på Vestlandet \\ John Roger Andersen \\ Professor\# \\ Avdeling for helsefag, Høgskulen på Vestlandet
}

\section{Anne Marie Sandvoll}

Førsteamanuensis

Institutt for helse- og omsorgsvitenskap, Høgskulen på Vestlandet, Førde

Siri Ytrehus

Professor

Avdeling for helsefag, Høgskulen på Vestlandet

Dokumentasjon

Fall

Sykehjem

Sykepleien Forskning 2017;12(62446):e-62446

DOI: 10.4220/Sykepleienf.2017.62446

\section{Sammendrag}

Bakgrunn: Førebygging av fall i sjukeheim er eit av hovudsatsingsområda i det nasjonale pasientsikkerheitsprogrammet, og dokumentasjon av fallrisiko er kravd.

Føremål: Føremålet med denne studien var å undersøke om dokumentasjonspraksis for fall i sjukeheimar er i samsvar med sjukeheimane sine eigne kriterium til dokumentasjon og kva faktorar som var assosiert med riktig dokumentasjonspraksis.

Metode: Retrospektiv deskriptiv metode er nytta i dette kvalitetsforbetringsprosjektet der dokumentasjon av fall i tre sjukeheimar vart kartlagt, og det vart undersøkt om dokumentasjonspraksisen deira var i tråd med sjukeheimane sine eigne kriterium til dokumentasjon.

Resultat: Av utvalet på 652 personar var det 208 (32 prosent) som hadde falle. Desse personane hadde til saman 556 registrerte fallepisodar. Fall med skade (smerte, kutt, brot) utgjorde 26 prosent av dei dokumenterte falla. Berre 10,6 prosent av falla var dokumenterte i tråd med sjukeheimane sine eigne dokumentasjonskriterium. Det var signifikante variasjonar i dokumentasjonspraksis mellom sjukeheimane, og brotskadar var assosiert med utfylling av skaderegistreringsskjema. 
Konklusjon: Resultata viser at sjukeheimane ikkje følgjer sine eigne dokumentasjonskriterium ved fall, men at fall med brotskadar var assosiert med riktig dokumentasjonspraksis.

Førebygging har lenge vore eit sentralt satsingsfelt for helsemyndigheitene og har vorte ytterlegare framheva i samhandlingsreforma med auka vektlegging av førebygging og betre samhandling mellom ulike aktørar i helsevesenet. Førebygging skal bidra til å unngå unødige plager for pasienten og unødige innleggingar i sjukehus (1).

Det nasjonale pasientsikkerheitsprogrammet «l trygge hender 24-7» har framheva fallførebygging som eit særskilt satsingsområde. Dette programmet har som mål å bidra til å redusere pasientskadar og auke pasienttryggleiken i Noreg (2). Programmet er ei vidareføring av ein omfattande nasjonal kampanje for pasienttryggleik i norsk helseteneste, som vart gjennomført i spesialist- og primærhelsetenesta i perioden 2011-2013. Helse- og omsorgsdepartementet var oppdragsgjevar, og kampanjen - som var frivillig for primærhelsetenesta - hadde tre hovudmål, som var å redusere talet på pasientskadar, bygge varige system og strukturar for pasienttryggleik og betre pasienttryggleikskulturen i helsetenesta. Pasientsikkerheitsprogrammet har tolv hovudsatsingsområde der førebygging av fall i sjukeheim og riktig legemiddelbruk i sjukeheim (legemiddelgjennomgang) er to av innsatsområda.

Sjølv om krava til kvalitet og strategiar for betring av helse- og sosialtenesta er kjende, er det gjentekne gonger påvist at det er gap mellom ønskt og reell praksis (3). Krav om sjukepleiedokumentasjon vert ikkje følgde, eller dokumentasjonen kan vere utilstrekkeleg og av dårleg kvalitet (4). Iverksetting av sekundærførebyggande tiltak kan difor vere mangelfull. Det er behov for å få meir kunnskap om dei sekundærførebyggande strategiane faktisk vert følgde i samband med fall, og meir kunnskap om faktorar som kan verke inn på arbeidet med å setje i verk fallførebyggande strategiar.

\section{Fall - eit alvorleg helseproblem for eldre}

Fall og fallskade kan definerast på ulike måtar. Ein definisjon som er nytta av norske myndigheiter, skildrar fall som ei utilsikta hending som medfører at ein person hamnar på bakken, golvet eller eit anna lægre nivå, uavhengig av årsak og om det oppstår skade som følgje av fallet (2). Fallskade definerast som kutt som krev suturering, skrubbsår og hudavskrap som krev behandling, forstuingar, mistanke om brot, brot og alle hovudskadar (2).

Denne artikkelen baserer seg på ein vidare analyse av data som var samla inn i samband med gjennomføring av ein klinisk revisjon ved tre norske sjukeheimar (5). Studien undersøkte medikamentvurdering knytt til fall og viste at 32 prosent av dei 652 undersøkte bebuarane hadde falle minst éin gong. Av dei 208 bebuarane som hadde falle, var det 46 prosent som hadde falle éin gong, medan 25 og 29 prosent hadde falle to gonger eller meir. Studien viste vidare store manglar i registreringa av fall. Dette viste seg ved at det var ei vesentleg underrapportering av fall $\mathrm{i}$ skaderegistreringsskjema (avviksmelding) samanlikna med fall som var rapporterte i journalen til pasienten. Dette vart ikkje inngåande undersøkt og drøfta i artikkelen, og gjev grunnlag for meir merksemd og spørsmål ved om kriteria for dokumentasjonspraksis for fall vert innfridde.

Fall er eit alvorleg helseproblem både blant eldre på sjukeheim og blant eldre som bur i eigen heim. 
Vidare er bakgrunnen for merksemda kring førebygging av fall også den kunnskapen vi i dag har om dei omfattande negative konsekvensane som fall kan ha for eldre. Fall er eit alvorleg helseproblem både blant eldre på sjukeheim $(6,7)$ og blant eldre som bur i eigen heim (8). Studiar viser at over ein tredjedel av eldre fell kvart år, at fallrisikoen aukar etter fylte 75 år, og at 50 prosent av eldre over 80 år har minst eitt fall i året $(7,9)$. Ein systematisk oversiktsartikkel viste at 10 til 20 prosent av falla hos eldre førte til alvorlege skadar som hovudtraume eller brot (7).

Merksemda om fall kjem også av at det er dokumentert at det er stort potensial for forbetring ved å innføre førebyggande tiltak i helseinstitusjonar (2). I Noreg er det innført ein eigen tiltakspakke for førebygging av fall (2). Denne tiltakspakken har - mellom mange andre tiltak - risikovurdering for fall og legemiddelgjennomgang som nokre av dei viktigaste tiltaka for fallførebygging.

\section{Førebygging og risikofaktorar}

For å nå målet om reduksjon av fall og fall med skade i helseinstitusjonar er det i dag føreslått sekundærførebyggande strategiar (10). Sekundærførebygging når det gjeld fall betyr mellom anna å identifisere dei som har auka risiko for fall. Dokumentasjon av fallrisiko er mellom anna naudsynt for å sikre at personen som har falle, får medikamentordinasjonen sin vurdert (5), at alle personar med forhøgd fallfare vert identifiserte, og at det kan bli gjennomført andre tiltak for å førebygge nye fall.

Vi har i dag mykje kunnskap om faktorar som påverkar fallrisiko $(7,11,12)$. Tidlegare fall er ein sentral risikofaktor for nye fall (2), saman med både indre risikofaktorar som helsetilstand og funksjonsnivå (13), og ytre faktorar som er særleg kjenneteikna ved omgivnadene (11). Dette medfører at det skal gjerast ei vurdering av fallrisikoen til pasienten dersom ein pasient allereie har falle ein gong (2).

Det vert anbefalt at denne typen risikovurdering vert utført som eit sekundærførebyggande tiltak for alle pasientar over 65 år og andre vaksne med nevrologiske eller kognitive sjukdomstilstandar eller vesentlege synshemmingar seinast eitt døgn etter innlegging eller etter første møte med pasient. Vurderinga skal utførast av sjukepleiar eller fagarbeidar. Fallrisiko skal vurderast på nytt dersom allmenntilstanden til pasienten endrar seg, ved fall eller minst éin gong per år for langtidspasientar. Fallrisiko skal dokumenterast i journalen til pasienten (2).

Føremålet med denne studien var difor å beskrive dokumentasjonspraksis for fall i sjukeheimar og drøfte i kva grad denne var i samsvar med sjukeheimane sine eigne kriterium til dokumentasjon. Vi ville vidare undersøke om alder og kjønn på bebuarane, sjukeheimsadresse, type fall og sjukehusinnlegging var assosiert med utfylling av skaderegistreringsskjema.

\section{Metode}

Dette kvalitetsforbetringsprosjektet vart gjennomført som ein retrospektiv deskriptiv studie av journalar og av skaderegistreringsskjema i tidsrommet 1. august 2010 til 31. juli 2011 ved tre sjukeheimar i ein stor norsk kommune. Dei skriftlege prosedyrane til sjukeheimane og dei uttalte kriteria for dokumentasjon av fall på datainnsamlingstidspunktet var at alle fall skulle dokumenterast etter dei gjeldande dokumentasjonsrutinane til sjukeheimane. Dette vil seie at fall skulle dokumenterast som ei uønskt hending, både i journal og i skaderegistreringsskjema, noko alle tilsette vart kjende med som eit ledd i opplæringa. Skaderegistreringsskjemaet sjukeheimane nyttar, er eit elektronisk journaldokument som skal innehalde alle data om fallet, som falldato, beskriving av hendinga, konsekvensen av fallet og vidare oppfølging. 
I kartleggingsperioden var 652 personar over 65 år lagde inn ved dei tre inkluderte sjukeheimane, og alle fall som var dokumenterte i journal, registrerte i skaderegistreringsskjema eller både i journal og skaderegistreringsskjema, vart registrerte. Sjukeheimane har til felles at dei nyttar same datasystem for all dokumentasjon og oppfølging av kvar einskild bebuar.

\section{Datainnsamling og variablane}

Datainnsamlinga gjekk føre seg ved at det vart samla inn opplysningar om fall frå anonymiserte journalar ved hjelp av alle skaderegistreringsskjema og fall som kom fram etter søk på orda «falt» og «ramlet» gjennom fritekst i journalane. Både journalane og skaderegistreringsskjemaa vart nøye gjennomgått og kontrollerte opp mot kvarandre. Denne registreringa resulterte i at ein fekk ei oversikt over alle falla per person slik dei var registrerte i både journalar og i skaderegistreringsskjema, og det var mogleg å få fram om falla var registrerte begge stader eller berre éin av stadene.

For kvar fallepisode vart det registrert om episoden var dokumentert i berre journal, berre i skaderegistreringsskjema eller begge stader. I tillegg til falldato vart det registrert alder og kjønn. Følgjene av fallet vart registrerte med variablane «skade» og «sjukehusinnlegging». Variabelen «skade» vart gitt verdiane "fall utan skade», "fall med skade utan brot (smerter og kuttskadar)» og «fall med brotskade». Variabelen «innlagd på sjukehus» vart gitt verdiane «innlagd på sjukehus» og «ikkje innlagd på sjukehus».

\section{Analyse}

Kategoriske variablar er presenterte som absolutte tal og prosent, medan kontinuerlege variablar er presenterte med gjennomsnitt og standardavvik. Det vart brukt multippel logistisk regresjon for å undersøke om alder, kjønn, praksisstad (sjukeheimane), skade ved fall og innlegging på sjukehus var assosiert med ikkje utfylt skaderegistreringsskjema etter fall. Odds ratio (OR) $>1$ indikerer auka risiko for ikkje å ha fylt ut skaderegistreringsskjema. Ein tosidig P-verdi $<0,05$ indikerer statistisk signifikans. SPSS versjon 20 vart brukt i dei statistiske analysane.

\section{Etiske aspekt}

REK såg prosjektet som ikkje søknadspliktig etter helseforskingslova, men sidan dette var eit internt kvalitetsforbetringsprosjekt utført av ekstern person, vart prosjektet lagt fram for Datatilsynet for juridisk avklaring. Datatilsynet gav uttrykk for at saka burde takast opp med Helsedirektoratet, som godkjende prosjektet. Godkjenninga vart gitt under føresetnad av at det vart nytta anonymiserte helseopplysningar, noko som vart etterlevd ved at alle data vart samla inn frå ein anonymisert versjon av databasane til sjukeheimane.

\section{Resultat}

Av 652 personar i utvalet var det 208 (32 prosent) som hadde falle, og som til saman hadde 556 registrerte fallepisodar (tabell 1). Dette viser at mange bebuarar hadde falle meir enn éin gong. Gjennomsnittsalderen for personane ved fallepisodane var 85,5 år. Dei fleste av falla var registrerte for kvinner (60,8 prosent). 
Tabell 1: Beskriving av fallepisodar sett opp mot bakgrunnsvariablar

Variablar

Sjukeheimar samla Sjukeheim A Sjukeheim B Sjukeheim C

$\begin{array}{lrrrr}\text { Alder, snitt } \pm \text { sd } & 85,5 \pm 6,8 & 84,9 \pm 7,3 & 87,2 \pm 5,9 & 85,6 \pm 6,1 \\ \text { Kvinner, } \mathbf{n}(\%) & 338(60,8) & 179(59,3) & 46(46,4) & 120(71,0)\end{array}$

Sjukeheim, n (\%)

Tal fall

$556(100)$

$302(54,3)$

$85(15,3)$

$169(30,4)$

Type fall, $\mathbf{n}(\%)$

Fall utan skade

$412(74,1)$

$225(74,5)$

$71(83,5)$

$116(68,6)$

Fall med skade utan brot

$109(19,6)$

$55(18,2)$

$12(14,1)$

$42(24,9)$

Fall med brotskade

$35(6,3)$

$22(7,3)$

$2(2,4)$

$11(6,5)$

Innlagt på sjukehus, $\mathrm{n}(\%)$

$26(4,7)$

$16(5,3)$

$3(3,5)$

$7(4,1)$

Fall beskrive i journal, $\mathrm{n}(\%)$

$508(91,4) \quad 273(90,4)$

$81(95,3)$

$154(91,1)$

Skaderegistreringsskjema utfylt, $n$ (\%)

$107(19,2)$

$72(23,8)$

$8(9,4)$

$27(16,0)$

Fall beskrive $i$ journal og skade-

registreringsskjema, $n$ (\%)

$59(10,6)$

$43(14,2)$

$4(4,7)$

$12(7,1)$

Fall utan skade utgjorde 74,1 prosent av falla. Fall med skade utan brot (smerter og kuttskadar) utgjorde 19,6 prosent, medan 6,3 prosent av falla enda med brotskade. For 26 av fallepisodane $(4,7$ prosent) vart pasienten lagd inn på sjukehus.

Gjennomsnittsalderen for personane ved fallepisodane var 85,5 år.

Vi fann at 91,4 prosent av fallepisodane var beskrivne i journal. Vidare var 19,2 prosent av falla dokumenterte i skaderegistreringsskjema. Totalt var 10,6 prosent av falla dokumenterte både i journalen og i skaderegistreringsskjema. 
Faktorar som var assosierte med skaderegistrering

Den logistiske regresjonsanalysen viste at det var statistisk signifikante forskjellar mellom sjukeheimane når det gjaldt kor ofte skaderegistreringsskjema vart fylt ut etter fall $(P=0,008)$ (tabell 2). 
Tabell 2: Logistisk regresjon med ikkje utfylt skaderegistreringsskjema som avhengig variabel $(N=556)$

Variablar

Ujustert OR

(95\% KI) P-verdi

Alder, per år

$0,98(0,95-1,01), P=0,202$

Justert OR

(95\% KI) P-verdi

Kjønn

Kvinner

Ref.

Menn

Sjukeheim

Sjukeheim A

Sjukeheim B

Sjukeheim C

Type fall, n (\%)

Fall utan skade

Fall med skade utan brot

Fall med brotskade

Innlagt på sjukehus

Nei

Ja
$1,48(0,95-2,32), P=0,085$

$P=0,007^{*}$

Ref.

$3,01(1,39-6,54), P=0,005$

$1,65(1,00-2,69), P=0,046$

$P=0,007^{*}$

Ref.

$0,82(0,48-1,40), P=0,475$

$0,31(0,15-0,64), P=0,002$

Ref.

$0,52(0,22-1,22), P=0,133$
Ref.

$0,98(0,95-1,01), P=0.230$

$1,42(0,98-2,37), P=0,137$

$P=0,008^{*}$

Ref.

$2,77(1,26-6,08), P=0,011$

$1,77(1,07-2,92), P=0,026$

$P=0,026^{*}$

Ref.

$0,84(0,49-1,45), P=0,531$

$0,21(0,07-0,65), P=0,007$

Merknad: * Overordna P-verdi for variablar med meir enn to verdiar. Verdiar $>1$ indikerer auka risiko for ikkje å ha fylt ut skaderegistreringsskjema. 
Det var vidare ein klar samanheng mellom kor alvorleg skaden av fallet var, og om det vart fylt ut skaderegistreringsskjema $(P=0,026)$. Det relative sannsynet for at skaderegistreringsskjema ikkje vart fylt ut, var lægre når fallet har resultert i brotskade, enn når fallet ikkje har resultert i skade $(O R=$ $0,21 ; P=0,007)$.

Det var ikkje nokon signifikant forskjell på det relative sannsynet for ikkje å fylle ut skaderegistreringsskjema om personen blei lagd inn på sjukehus eller ikkje etter fall $(\mathrm{OR}=0,45 ; \mathrm{P}=$ 0,242).

\section{Diskusjon}

Føremålet med denne undersøkinga var å studere i kva grad praksis ved sjukeheimane er i tråd med sjukeheimane sine eigne kriterium til dokumentasjon av fall og kva faktorar som var assosierte med dette.

Vi såg at flest fall gjaldt kvinner. Dette må sjåast i lys av den store prosentdelen kvinner på sjukeheim. Fallrisikoen aukar etter 75 års alder, og 50 prosent av eldre over 80 år fell minst éin gong årleg (9). Det same viser resultata her. Gjennomsnittsalderen ved fallepisodane var 85,5 år, noko som indikerer at dette kan vere ei utsett gruppe, og som i tillegg peikar på behovet for naudsynt oppfølging.

Berre 10,6 prosent av falla har vore dokumenterte både i journal og i skaderegistreringsskjema. Resultatet frå denne studien viser at praksisen ved sjukeheimane ikkje er i tråd med kriteria som er stilte til kva som skal dokumenterast ved fall. Berre 10,6 prosent av falla har vore dokumenterte både i journal og i skaderegistreringsskjema, som er sjukeheimane sine eigne uttalte kriterium til dokumentasjon av fall. Studien viser derimot at det er variasjon mellom sjukeheimane i etterlevinga av kriteria for dokumentasjon av fall, og at meir alvorlege fall er assosierte med betre etterleving.

\section{Mangelfull registrering av fall}

Det er fleire grunnar til at det i dag blir stilt krav til at fall hos eldre skal registrerast, og at det skal gjennomførast risikovurderingar etter at eldre har falle. Først og fremst gir dette moglegheit for å setje i verk førebyggande tiltak. Ei risikovurdering vil omfatte ein systematisk gjennomgang av ulike risikofaktorar for fall, både indre og ytre, mellom anna medikamentordinasjonen til den eldre (5). Mangelfull registrering kan bety at det ikkje vert gjennomført risikovurderingar, slik at nødvendige førebyggande tiltak kan setjast i verk. Mangelfull registrering av fall medfører at ein heller ikkje får kunnskap om omfanget av problemet og kva konsekvensar dette problemkomplekset har for samfunnet.

Det kan vere fleire årsaker til at fall ikkje vert dokumenterte i tråd med kriteria i sjukeheimane. Forskinga om risikofaktorar gir kunnskap om kva som er nødvendige førebyggande tiltak. Ei årsak kan vere at tilsette ikkje har denne kunnskapen. Personalet kan mangle kunnskap om både krav til korleis fall skal dokumenterast, og om dei alvorlege negative konsekvensane som eit fall kan medføre for eldre (14). Dermed vil dei heller ikkje ha forståing for nødvendigheita av registreringar. Følgjeleg er dei ikkje lojale mot kriteria til dokumentasjon.

Undersøkinga her har studert om fall vert dokumentert i tråd med kriteria sjukeheimane sjølve har bestemt. Vi kan dermed ikkje sjå bort frå at risikovurderingar og nødvendige endringar vert gjennomført utan at dette vert dokumentert. I så fall vil årsaka til manglande dokumentasjon skuldast mangel på kunnskap om kvalitetsarbeid og dokumentasjon, og ikkje mangel på kunnskap om fallrisiko og førebygging. Vi har lite kunnskap om korleis tilsette på sjukeheim vurderer og stiller seg i høve til det å skulle registrere avvik. Det kan vere at sjølve avviksregistreringa kan opplevast som ekstraarbeid eller belastande på andre måtar, dersom det ikkje er etablert ein positiv kultur for dette. 


\section{Årsaker til manglande dokumentasjon}

Samanhengen mellom kor alvorlege følgjene av fallet er og om det vert fylt ut skaderegistreringsskjema, kan indikere at personalet ved sjukeheimane ikkje er godt nok kjende med sine eigne dokumentasjonskriterier i forhold til å registrere uønskte hendingar (avvik). Samstundes har vi sett at det først var når fallet førte til skade, at det vart tilfredsstillande dokumentert. Dette kan tyde på at ei medverkande forklaring kan vere mangel på forståing for tydinga av førebygging og samanhengen mellom avviksregistrering og kvalitetsforbetring (15).

Det var først når fallet førte til skade, at det vart tilfredsstillande dokumentert.

Den signifikante forskjellen mellom sjukeheimane i sannsyn for at skaderegistreringsskjema vert utfylt, kan skuldast kulturforskjellar. Pasientsikkerheitsprogrammet er også opptatt av at pasienttryggleiken vert påverka av mange ulike forhold på ein arbeidsplass, og har pasienttryggleikskultur som eitt av sine tre mål (2). Det kan òg skuldast ulikt kunnskapsnivå som for eksempel kan vere forårsaka av vanskar med rekruttering av personell med relevant kompetanse, og ulikt fokus på fallførebygging frå dei ulike leiingane si side. Alle dei inkluderte sjukeheimane var i same kommune, noko som skulle indikere like gode rekrutteringsmoglegheiter til kompetent personell for alle sjukeheimane. Det er difor rimeleg å anta at dei forskjellane mellom sjukeheimane heller skuldast kulturforskjellar og ulikt fokus på fallførebygging frå leiinga si side.

Andre årsaker til manglande registrering kan vere manglande merksemd kring den heilskaplege implementeringsprosessen. Fallførebyggande praksis med krav om dokumentasjon og risikovurderingar er innovasjonar som kan representere nye måtar å arbeide på. Å implementere ein ny praksis er aldri enkelt. Forsking om fall har gitt oss kunnskap om risikofaktorar og fallførebygging, men denne forskinga gir ikkje kunnskap om korleis ein skal gå fram for å implementere tiltaka. Rein kunnskapsoverføring er ikkje alltid nok for å endre praksis (16-18). Ved innføring av fallførebyggande intervensjonar må organisasjonen ha merksemd på heile implementeringsprosessen (19).

Endring av praksis kan krevje at det vert tilrettelagt for ei kompetanseutvikling som er tilpassa den spesifikke konteksten, med oppfølging, rettleiing, involvering av og støtte til dei som skal gjennomføre intervensjonen $(16,17,20)$, samt å tilpasse implementeringa til den spesifikke praktiske konteksten (21). I denne prosessen vil leiinga ved institusjonane vere sentral. Manglande merksemd i leiinga på heilskapen i implementeringa kan vere ei medverkande årsak til manglande dokumentasjon (22). Sjølvsagt vil tidspress, stor arbeidsbyrde og manglande kunnskap om sjukepleiedokumentasjon spele ei rolle $(23,24)$. Vidare hindrar stadige avbrytingar når ein dokumenterer og mangel på rettleiing god sjukepleiedokumentasjon (25). Desse barrierane er det viktig å vere klar over, slik at tiltaka i ein kvalitetsforbetringsstrategi kan rette seg direkte mot barrierane (26).

\section{Avgrensingar og styrkar ved studien}

Resultata frå denne studien skildrar praksis i eit avgrensa tidsrom ved berre tre norske sjukeheimar. Dette tilseier at ein må vere særleg forsiktige med å generalisere resultata til å gjelde andre sjukeheimar. Det er vidare rimeleg å tru at resultatet kunne vorte annleis dersom studien blei gjennomført etter iverksetting av pasientsikkerheitsprogrammet. Datasystemet som sjukeheimane nyttar, er svært godt tilrettelagt for uthenting av data, og mange data er importerte direkte frå databasen inn i analyseverktøyet. Registreringsfeil som kan følgje av manuell registrering av data vart dermed unngått. 
Denne artikkelen baserer seg på journalopplysningar. Det kan ha vorte gjort feilregistreringar, og feil definisjon av fall kan ha vorte lagt til grunn. Det er mogleg at nokon har definert fall som fall med skade, og fall kan ha vorte beskrive med andre ord enn «falt» og «ramlet». Dette er moglege feilkjelder som kan bety ei underrapportering av fall. Vidare kan den ikkje signifikante assosiasjonen ved sjukehusinnlegging og utfylling av skaderegistreringsskjema $(O R=0,45)$ (Tabell 2), vere ein type 2 feil, grunna låg statistisk styrke.

\section{Vegen vidare}

Resultata frå denne studien viser at sjukeheimane har eit stort forbetringspotensial når det gjeld dokumentasjon av fall. Det er grunn til å tru at ein ved opplæring i dokumentasjonsrutinane kan forbetre dokumentasjonspraksis, ettersom fleire systematiske oversikter viser at undervisningsintervensjonar kan betre kvaliteten i sjukepleiedokumentasjon $(4,27)$. Vidare kan tilbakemelding vere ein del av undervisningsintervensjonen der resultat frå gransking av praksis vert formidla til personalet, slik at personalet vert motivert til å gjere ein innsats for å tette gapet mellom det forsking seier om kvalitet i sjukepleiedokumentasjon og praksis $(28,29)$.

Dette vert understreka gjennom forsking som syner at audit og tilbakemelding kan vere effektivt for å forbetre praksis dersom det er stor avstand mellom den praksisen som vert utført og anbefalt praksis (30) noko som er tilfelle i denne studien. I tillegg vil det vere viktig at ein i det vidare fallførebyggande arbeidet rettar merksemda mot heilskapen i implementeringsprosessen, og dermed mot å skape ein kultur for pasienttryggleik i helsetenesta. Vi har behov for meir forsking om korleis implementeringa faktisk skjer på sjukeheimane, både når det gjeld fallførebyggande intervensjonar og andre intervensjonar, samt om vellykka implementeringsprosessar og kva som kjenneteiknar desse.

\section{Konklusjon}

Måling av kvalitet ved tre sjukeheimar i Noreg synte stort avvik mellom kriterier og reell praksis. Berre 10,6 prosent av falla har vore dokumenterte etter sjukeheimane sine eigne kriterier. Sjølv om nokon forbetringar allereie kan vere iverksette som følgje av pasientsikkerheitsprogrammet, indikerer dette likevel at det er behov for opplæring, repetisjon av kriterium og rutinar og tilbakemelding på korleis rutinane vert overhaldne, i tillegg til ein heilskapleg prosess for å setje dei i verk.

Denne studien spring ut frå ei mastergradsoppgåve i kunnskapsbasert praksis i helsefag ved Høgskolen i Bergen, Senter for kunnskapsbasert praksis. Takk til Monica W. Nortvedt, Birgitte Espehaug og Katrine Aasekjær som var rettleiarar for oppgåva for hjelp til gjennomføring av prosjektet. Takk også til programutviklar og systemansvarleg for datasystemet ved sjukeheimane, Magne Rekdal i Emetra AS, for opplæring i datasystemet og for hjelp til uttrekk av data.

\section{Referansar}

1. Helse- og omsorgsdepartementet. Samhandlingsreformen. Helse- og omsorgsdepartementet, Oslo. 2008.

2. Helsedirektoratet. Forebygging av fall i helseinstitusjoner 2015. Tilgjengeleg frå: http://www.pasientsikkerhetsprogrammet.no/no/l+trygge+hender/Innsatsomr\%C3\%A5der/forebyggingav-fall-i-helseinstitusjoner;jsessionid=72C5D43A140951BDD3263E6C10BCE32A. (Lasta ned

21.12.2015.)

3. Sosial- og helsedirektoratet. ... OG BEDRE SKAL DET BLI!: nasjonal strategi for kvalitetsforbedring i Sosial- og helsetjenesten (2005-2015). Sosial- og helsedirektoratet, Oslo. 2005. 
4. Saranto K, Kinnunen UM. Evaluating nursing documentation - research designs and methods: systematic review. J Adv Nurs. 2009;65(3):464-76.

5. Øygard SH, Nortvedt MW, Espehaug B, Aasekjær K. Samsvar mellom praksis og retningslinje for førebygging av fall og vurdering av medikamentordinasjon på sjukeheim. Sykepleien Forskning. 2013;8(3):242-8.

6. Stevens JA, Corso PS, Finkelstein EA, Miller TR. The costs of fatal and non-fatal falls among older adults. Inj Prev. 2006;12(5):290-5.

7. Sterke CS, Verhagen AP, van Beeck EF, van der Cammen TJ. The influence of drug use on fall incidents among nursing home residents: a systematic review. Int Psychogeriatr. 2008;20(5):890-910.

8. Boyé ND, Van Lieshout EM, Van Beeck EF, Hartholt KA, Van der Cammen TJ, Patka P. The impact of falls in the elderly. Trauma. 2013;15(1):29-35.

9. Helsedirektoratet. Fallforebygging i kommunen. Kunnskap og anbefalinger. Helsedirektoratet, Oslo. 2013. Tilgjengeleg frå:

https://helsedirektoratet.no/Lists/Publikasjoner/Attachments/98/Fallforebygging-i-kommunenkunnskap-og-anbefalinger-IS-2114.pdf. (Lasta ned 25.06.2017).

10. Cameron ID, Gillespie LD, Robertson MC, Murray GR, Hill KD, Cumming RG et al. Interventions for preventing falls in older people in care facilities and hospitals. The Cochrane Library. 2012.

Tilgjengeleg frå: http://www.cochrane.org/CD005465/MUSKINJ_interventions-for-preventing-falls-inolder-people-in-care-facilities-and-hospitals. (Lasta ned 26.06.2017).

11. Kenny RA. Mobility and falls. The Cambridge handbook of age and ageing. Cambridge University Press, Cambridge. 2005. (s. 131-40).

12. Woolcott JC, Richardson KJ, Wiens MO, Patel B, Marin J, Khan KM et al. Meta-analysis of the impact of 9 medication classes on falls in elderly persons. Archives of Internal Medicine. 2009;169(21):1952-60.

13. Bergland A. Fall risk factors in community-dwelling elderly people. Norsk epidemiologi. 2012;22(2):151-64.

14. Phillips VL, Roberts DY, Hunsaker AE. Certified nursing aides' and care assistants' views on falls: Insight for creation and implementation of fall prevention programs. Journal of the American Medical Directors Association. 2008;9(3):168-72.

15. Wagner LM, Capezuti E, Taylor JA, Sattin RW, Ouslander JG. Impact of a falls menu-driven incident-reporting system on documentation and quality improvement in nursing homes. The Gerontologist. 2005;45(6):835-42.

16. Fixsen D, Scott V, Blase K, Naoom S, Wagar L. When evidence is not enough: The challenge of implementing fall prevention strategies. Journal of Safety Research. 2011;42(6):419-22.

17. Etheridge F, Couturier $Y$, Denis J-L, Tremblay L, Tannenbaum C. Explaining the success or failure of quality improvement initiatives in long-term care organizations from a dynamic perspective. Journal of Applied Gerontology. 2014;33(6):672-89.

18. Fretheim A, Flottorp S, Oxman A. Effekt av tiltak for implementering av kliniske retningslinjer. Rapport fra Kunnskapssenteret nr. 10-2015. Oslo: Nasjonalt kunnskapssenter for helsetjenesten; 2015. 
19. Wagner LM, Dionne JC, Zive JR, Rochon PA. Fall risk care processes in nursing home facilities. Journal of the American Medical Directors Association. 2011;12(6):426-30.

20. Szczerbinska K, Zak M, Ziomkiewicz A. Role of method of implementing multi-factorial falls prevention in nursing homes for elderly persons. The EUNESE Project. Aging Clinical and Experimental Research. 2010;22(3):261-9.

21. Neyens JC, van Haastregt JC, Dijcks BP, Martens $M$, van den Heuvel WJ, de Witte LP et al. Effectiveness and implementation aspects of interventions for preventing falls in elderly people in long-term care facilities: a systematic review of RCTs. Journal of the American Medical Directors Association. 2011;12(6):410-25.

22. Rask K, Parmelee PA, Taylor JA, Green D, Brown H, Hawley J et al. Implementation and evaluation of a nursing home fall management program. Journal of the American Geriatrics Society. 2007;55(3):342-9.

23. Björvell $\mathrm{C}$, Wredling $\mathrm{R}$, Thorell-Ekstrand I. Improving documentation using a nursing model. Journal of Advanced Nursing. 2003;43(4):402-10.

24. Naustdal A-G, Netteland G. Sjukepleiedokumentasjon i eit elektronisk samhandlingsperspektiv. Sykepleien Forskning. 2012;7(3):270-7.

25. Paans W, Sermeus W, Nieweg RM, van der Schans CP. Prevalence of accurate nursing documentation in patient records. J Adv Nurs. 2010;66(11):2481-9.

26. Burgess R. New principles of best practice in clinical audit. 2. utgave. Radcliffe Publishing, Oxford. 2011.

27. Wang N, Hailey D, Yu P. Quality of nursing documentation and approaches to its evaluation: a mixed-method systematic review. Journal of Advanced Nursing. 2011;67(9):1858-75.

28. Straus S, Tetroe J, Graham ID, red. Knowledge translation in health care: moving from evidence to practice. Wiley-Blackwell, Oxford. 2009.

29. Flottorp S, Jamtvedt G, Gibis B, McKee M. Using audit and feedback to health professionals to improve the quality and safety of health care. World Health Organization, København. 2010.

Tilgjengeleg frå: http://www.euro.who.int/_data/assets/pdf_file/0003/124419/e94296.pdf?ua=1. (Lasta ned 20.12.2015.)

30. Ivers N, Jamtvedt G, Flottorp S, Young JM, Odgaard-Jensen J, French SD et al. Audit and feedback: effects on professional practice and healthcare outcomes. The Cochrane database of systematic reviews. 2012;6:Cd000259. 


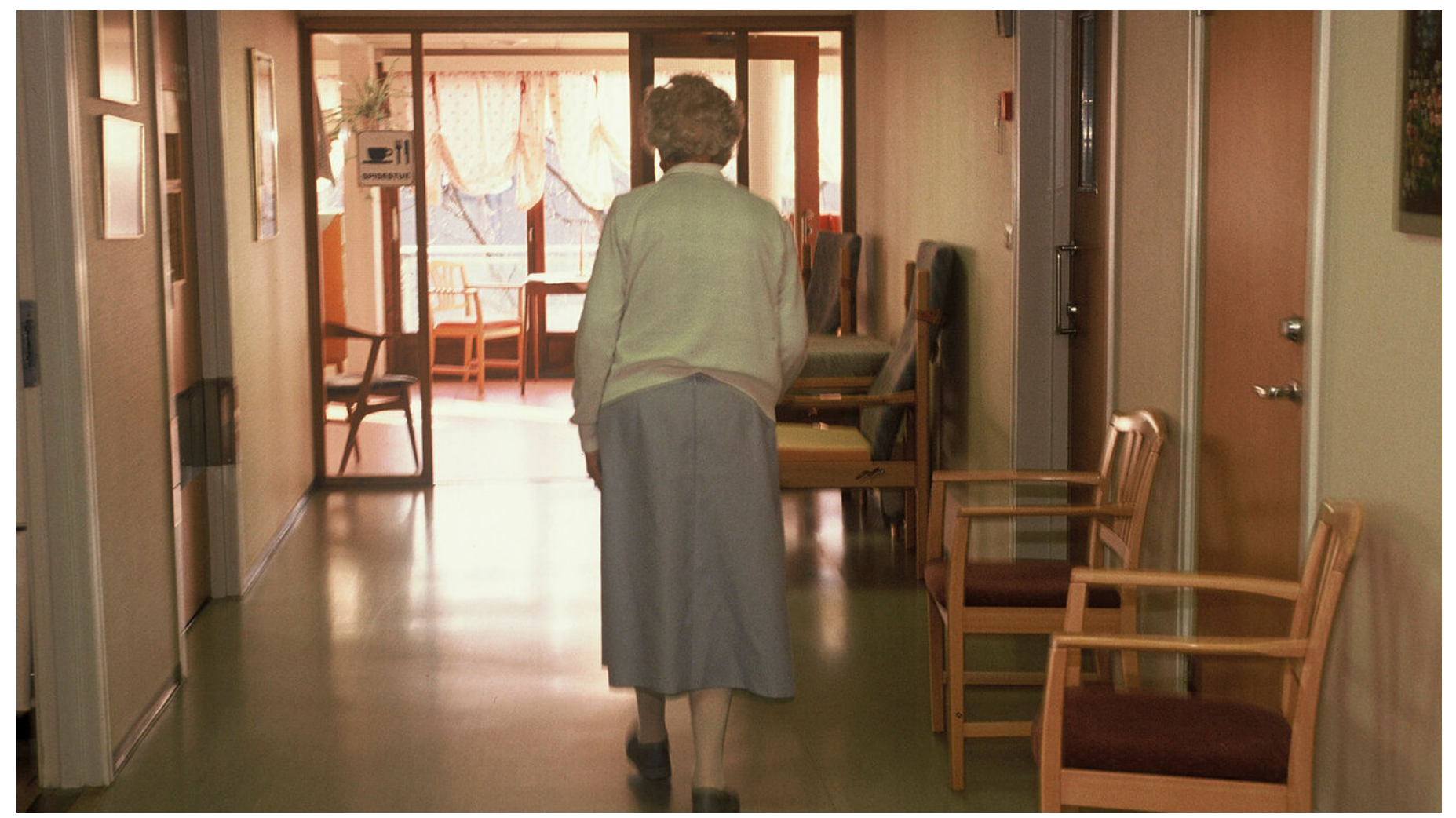

SERIOUS HEALTH PROBLEM: One third of the elderly population experience a fall every year,... LES MER $\checkmark$ 